\title{
Optimization of Drop-and-Pull Transport Network Based on Shared Freight Station and Hub-and- Spoke Network
}

\author{
Mei Feng ${ }^{1,2}$, Yaorong Cheng ${ }^{1 *}$ \\ ${ }^{1}$ Traffic and Transportation Engineering of Central South University, Changsha 410075, China \\ ${ }^{2}$ Hunan Vocational College of Modern Logistics, Changsha 410131, China
}

Corresponding Author Email: yaorong@csu.edu.cn

https://doi.org/10.18280/jesa.520504

Received: 17 April 2019

Accepted: 22 July 2019

\section{Keywords:}

drop-and-pull (D-P) transport, hub-andspoke $(H-S)$ network, shared freight station, optimization

\begin{abstract}
The current drop-and-pull (D-P) transport process has many defects, including but not limited to the insufficient information sharing, the private ownership of vehicles and infrastructure, and the mismatch between vehicles and goods. Moreover, the hardware and software of existing freight stations fall short of the demand for D-P transport. To solve these problems, this paper optimizes the design of the D-P transport network based on shared freight station and the hub-and-spoke (H-S) network. The freight stations were taken as the hubs, and the routes between supply/demand point and freight station are treated as spokes. On this basis, an optimization model was established to minimize the total cost of freight stations and maximize the force from freight stations on supply/demand points in the H-S D-P network. In addition, all the supply/demand points in the region are covered by the selected freight stations. The LINGO software was introduced to solve the established model. Taking a region in southern China for example, the proposed shared freight station design was compared with the traditional freight station design. The results show that the single-hub H-S D-P network obtained by the traditional design could meet the demand when the D-P demand was relatively small; however, only the multi-hub H-S D-P network obtained by the shared freight station design could fulfil a large D-P demand in an efficient manner. The research findings show that the shared freight station is the future of D-P transport.
\end{abstract}

\section{INTRODUCTION}

According to The General Administration of Quality Supervision, Inspection and Quarantine of the People's Republic of China, drop-and-pull (D-P) transport is defined as a transportation mode that two trailers are pulled in turn by the same tractor to their respective destinations. The D-P transport can effectively improve the transport efficiency, reduce the transport cost and shorten the transport time.

This advanced transportation mode provides a desirable way to speed up logistics service and promote energy saving and emissions reduction. The benefits of the D-P transport can be maximized if the vehicles, traffic network, and transport industry are mature and standardized. As a result, most large freight enterprises have adopted the D-P transport in developed countries like the UK, the US and Japan.

In the D-P transport system, the freight station serves as the center for the distribution and organization of goods. The operations of the freight station directly affect the transit, distribution and storage links in the system. Therefore, the site of the station must be selected properly, making the D-P transport more organized, rational and comprehensive.

In recent years, the D-P transport has made marked progress due to the advancement of the Internet technology, big data and cloud computing. The most prominent progress is the emerging D-P transport network, which reflects the concepts of truck pooling, station renting and information sharing.

The efficiency of the D-P transport network hinges directly on the planning and construction of the so-called shared freight station. This new type of freight station optimizes the cost and scope of resource transaction by sharing infrastructure, vehicles and information.

The current D-P transport process has many defects, including but not limited to the insufficient information sharing, the private ownership of vehicles and infrastructure, and the mismatch between vehicles and goods.

Moreover, the hardware and software of existing freight stations fall short of the demand for D-P transport. For example, many freight stations are located in wrong places, which are far from large goods distribution centers and loosely connected with support facilities.

To solve the above problems, this paper optimizes the design of the D-P transport network based on shared freight station and the hub-and-spoke (H-S) network.

\section{LITERATURE REVIEW}

\subsection{Relevant studies on the D-P transport}

The existing studies on the D-P transport mainly focus on three aspects: vehicle safety, route optimization and vehicle performance.

On vehicle safety, Vlk [1] divided driver operations into turning, braking and turning-braking, investigated how these operations affect the safety of the D-P vehicle system, and concluded that D-P vehicles are prone to accidents in the turning process. Godbole et al. [2] identified the influencing 
factors of the dynamic load of D-P vehicles, including load level, position of mass center, suspension setting and damping of vibration components, and explored their impacts on the vertical motion of the chassis of the tractor. Salati et al. [3] carried out wind tunnel experiments on heavy duty trucks with trailer connectors on both front and rear axles, and studied the aerodynamic drag of European heavy duty trucks.

On route optimization, Wang and Chan [4] developed a multi-objective integer programming model for the D-P transport of multiple goods, which optimizes the number of vehicles, finds the most effective routes, and minimizes the energy and operational costs. To satisfy different consumer demands, Villegas et al. [5] obtained multiple optimal routes through partitioned scheduling of D-P services. Similarly, Derigs et al. [6] analyzed several vehicle routing problems (VRPs) with load constraint or time window, combined a heuristic algorithm with local search and neighborhood search to solve the problems, and verified the feasibility and accuracy of the combined method through example analysis. Mirmohammadsadeghi and Ahmed [7] probed into a tractor and trailer routing problem (TTRP) with random demand and time window. Galić et al. [8] introduced an informatized vehicle path optimization system to solve the distribution problem of fast-moving consumer goods (FMCGs), which trims the cost, reduces the number of depots, and enhances consumer satisfaction without increasing the number of distribution vehicles.

On vehicle performance, Vlk [9] simulated the response time and operation method of drivers on unbalanced vehicles. Pflug [10] conducted 3D simulations how different combinations of tractor and trailer change in lateral stability, damping performance and vibration frequency, under extreme driving conditions. Kim et al. [11] disclosed the mechanism of drag reduction by analyzing the precursor of the vehicle model, laying the basis for the design of new conditional random field (CRF) models and the improvement of aerodynamic performance of heavy vehicles.

\subsection{Relevant studies on freight station design}

There are relatively a few studies on the site selection and design of freight stations in the D-P network. Based on minmax formulation, Horta et al. [12] designed a mathematical program that returns the optimal design of a cross-docking warehouse for just-in-time distribution. Rakesh and Adil [13] developed an algorithm that the lane depth, number of storage levels, lateral depth and longitudinal width of a 3D order picking warehouse, aiming to minimize the space occupation and handling cost. Melo et al. [14] put forward a multi-stage site selection model for freight stations. Zhong et al. [15] established a mathematical model to select the site of freight stations, solved the model with genetic algorithm (GA), and evaluated the optional sites through Arena-based simulation. Using VisSim program, Zhou et al. [16] built a traffic simulation model of D-P transport terminal for coastal ports of China, and examined the traffic conditions and functional design of the terminal.

\subsection{Relevant studies on vehicle sharing}

Sharing is a hot topic in recent years. Numerous shared products have emerged, ranging from shared bicycles to shared power banks. The sharing frenzy has not spread to freight stations, because of the special locations, scale of equipment and difficulty in benefit allocation. Shared trailers are now available in only a few logistics enterprises. The previous research on vehicle sharing mainly focuses on bicycles and cars.

Based on the Petri net, Labadi et al. [17] created a discrete event model to evaluate the performance of public bicycle sharing systems. Yang et al. [18] studied the impact of public bicycle sharing systems on the original public transport network in urban areas. Considering the spatial-temporal variation of car-sharing demand, Mohammadi and Shirouyehzad [19] developed a multi-goods, multi-period model based on the travelling salesman problem (TSP), and utilized the model to rebalance the bicycle sharing. Zhu et al. [20] optimized the depot locations with an approach to cover the spatial-temporal demand.

To sum up, there are only a few qualitative studies on the design of freight stations in the D-P transport network, not to mention the site selection of shared freight stations. What is worse, the previous research mostly tackles the turnover of goods. In this paper, the research object is changed to the number of trailers, a more representative indicator of the D-P transport.

For the above reasons, this paper puts forward a design of shared freight station based on the H-S network, according to the T-P demand in a region in southern China and in the light of the previous results on freight station design. Under the premise of sharing the infrastructure, a freight station design model was established to cover all supply and demand points with the minimal cost and maximal applied force. The model was solved by the LINGO software. Empirical results show that the shared freight station can be utilized more thoroughly than the traditional freight station.

\section{MODEL ESTABLISHMENT}

\subsection{T-P transport network based on the H-S network (H-S T-P network)}

The H-S network is a system of multiple nodes and routes. In this network, the goods must arrive at a central location (hub), i.e. the freight station, whether they are transported from different supply points (origins) or the same supply point (origin) to different demand points (destinations). The goods will be directly transported to the demand points from the freight station. The route between each supply/demand point and the freight station is considered as a spoke in the network. The H-S network aims to concentrate the traffic flow and realize the economy of scale.

In the H-S T-P network, most nodes can achieve the transmission of personnel, goods and services through the interaction with one or several freight stations. Depending on the number of freight stations, the H-S T-P networks can be divided into single-hub H-S T-P network or multi-hub H-S T$P$ network.

In a single-hub $\mathrm{H}-\mathrm{S}$ T-P network (Figure 1), each supply/demand point is connected to only one transfer station. The vehicles from a supply point can only travel to the demand points via the only transfer station. In this network, a transfer station serves several supply points or demand points. The same supply/demand point cannot be served by multiple transfer stations. The transfer station is semi-shared.

In a multi-hub H-S T-P network (Figure 2), each supply/demand point is connected to more than one freight 
stations. The vehicles from a supply point can travel through any of the freight stations as long as it is idle.

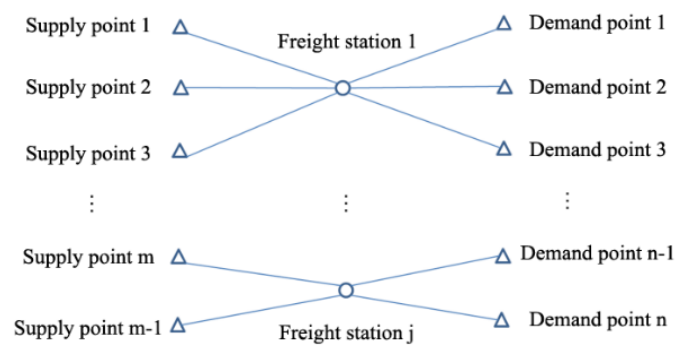

Figure 1. Single-hub H-S T-P network

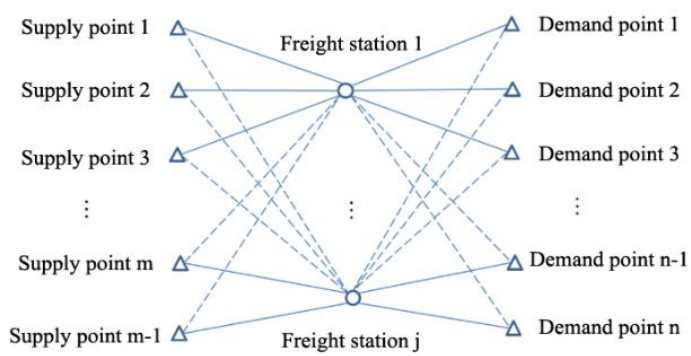

Figure 2. Multi-hub H-S T-P network

This paper aims to optimize the design of shared transfer station(s), while satisfying the supply and demand of all points in the H-S T-P network.

\subsection{Model of traditional freight station design in the H-S T- P network}

\subsubsection{Hypotheses}

The following hypotheses were put forward before modelling traditional freight station design in the H-S T-P network:

(1) The freight station is selected from a limited number of alternatives.

(2) All supply/demand points must be connected to all freight stations, that is, the goods between any pair of supply and demand points must go through a freight station.

(3) The capacity, i.e. the maximum accommodatable number of trailers, of each freight station can satisfy the demand.

(4) The transport fee is the same in the region.

(5) The transfer between freight stations is not considered in the region.

(6) The total D-P cost in the region includes the transfer station construction cost, the transfer station management cost and the transport cost.

\subsubsection{Symbols and decision variables}

The symbols used for the modelling are described below:

$U$ is the total D-P cost in the region; $r$ is the transport fee; $D_{i j}$ is the distance from supply point $i$ to the alternative freight station $j ; D_{j k}$ is the distance from the alternative freight station $j$ to the demand point $k ; X_{i j}$ is the number of trailers from supply point $i$ to the alternative freight station $j ; Y_{j k}$ is the number of trailers from the alternative freight station $j$ to the demand point $k ; g$ is the monthly management cost per alternative transfer station; $S_{j}$ is the construction cost of alternative freight station $j ; M_{j}$ is the capacity of alternative freight station $j ; A_{i}$ is the number of trailers in the supply point $i ; B_{k}$ is the number of trailers in demand point $k$. Note that supply point and demand point refer to the origin and destination of goods in trailers, respectively.

The decision variables for the modelling are described: $I=\{1,2, \ldots, m\}, J=\{1,2, \ldots, n\}$ and $K=\{1,2, \ldots, q\}$ are the sets of supply points, alternative freight stations and demand points, respectively.

$$
P_{j}= \begin{cases}1 & \text { If alternative freight station } \mathrm{j} \text { is selected; } \\ 0 & \text { Otherwis. }\end{cases}
$$

\subsubsection{Model construction}

(1) Objective function

Cost minimization is a common objective in many VRPs [21]. The objective to minimize the D-P cost in the region can be expressed as:

$$
\min U=\sum_{i=1}^{m} \sum_{j=1}^{n} r D_{i j} X_{i j}+\sum_{j=1}^{n} \sum_{k=1}^{q} r D_{j k} Y_{j k}+\sum_{i=1}^{m} \sum_{j=1}^{n} g X_{i j}+\sum_{j=1}^{n} P_{j} S_{j}
$$

Then, another objective can be established to maximize the force from the selected freight station acting on supply and demand points.

Based on logistics field theory, the field strength $\vec{E}_{\mathrm{ij}}$ of freight station $j$ at supply point $i$ can be described as:

$$
\overrightarrow{E_{i j}}=K_{j} \frac{Q_{j}}{D_{i j}^{2}} \vec{n}
$$

where, $K_{j}$ is the logistics factor; $Q_{j}$ is the scale of freight station $j ; \vec{n}$ is the unit direction vector. The logsitics factor is an integrated weighted value of the various factors affecting the strength of the logistics field, namely, economic strength, geographic location and traffic conditions [22]. Here, the $K_{j}$ value of each alterantive frieght station is computed by Jin's method [23], based on the data in the statistical yearbook of the region. The scale of freight station equals the capacity of that station, $M_{j}$. The value of $\vec{n}$ is one, and the direction of $\vec{n}$ is the logsitics direction.

Then, the force from freight station $j$ acting on supply point $i$ can be calculated as:

$$
\vec{F}_{i j}=X_{i j} \vec{E}_{i j}=K_{j} \frac{X_{i j} Q_{j}}{D_{i j}^{2}} \vec{n}
$$

where, $\vec{n}$ is negligible, because direction is not considered in our research.

Drawing on the breaking-point-ring theory, the forces $F_{1}$, $F_{2}, \ldots, F_{n}$ from $\mathrm{n}$ freight stations $P_{1}, P_{2}, \ldots, P_{n}$ in the region acting on supply point $i$ satisfies:

$$
F=\operatorname{Max}\left\{F_{1}, F_{2}, \ldots, F_{n}\right\}
$$

Under ideal conditions, each supply point should select the freight station that exerts the largest force on it for goods transfer. However, this is impossible for all supply points, due to the limited capacity of each freight station per day. Therefore, this expectation was modified as maximizing the overall force $F$ acting on all supply/demand points. 


$$
\operatorname{Max} F=\sum_{i=1}^{m} \sum_{j=1}^{n} F_{i j}+\sum_{j=1}^{n} \sum_{k=1}^{q} F_{j k}
$$

where, $F_{i j}$ is the force of freight station $j$ acting on supply point $i ; F_{j k}$ is the force of freight station $j$ acting on demand point $i$.

(2) Constraints

Each freight station should fully cover all supply/demand points. The coverage rate of freight stations was calculated based on the coverage computation for buses.

For a bus station, its coverage is equivalent to the size of the circle centering on the bus station with a suitable walking distance (generally $300 \mathrm{~m}$ ) as the radius, or the size of the rectangle with the bus route as the horizontal line of symmetry and a suitable walking distance (generally $500 \mathrm{~m}$ ) as the width Thus, the coverage rate $f$ of a bus station can be computed by:

$$
f=\frac{\sum_{i=1}^{n} a_{i}}{E}
$$

where, $n$ is the number of bus routes or bus stations; $a$ is the coverage of each bus route or bus station; $E$ is the total area of the region.

Similarly, the coverage of a freight station was considered a circle centering on the station. The coverage $H_{j}$ of freight station $j$ can be computed by:

$$
H_{j}=K_{j}^{*} \pi C^{2}
$$

where, $C$ is the economically feasible transport distance of the freight station $(\mathrm{km})$.

The coverage rate $\alpha$ of a freight station should subjected to the following constraint:

$$
\frac{\sum_{j=1}^{n} P_{j} K_{j} \pi C^{2}}{E} \geq \alpha
$$

The other constraints are as follows:

$$
\begin{gathered}
A_{i}=P_{j} X_{i j} \quad(j=1,2, \ldots \ldots n) \\
B_{k}=P_{j} Y_{j k} \quad(j=1,2, \ldots \ldots n) \\
P_{j} M_{j}-P_{j} \sum_{i=1}^{m} X_{i j} \geq 0 \quad(j=1,2, \cdots, n) \\
\sum_{j=1}^{n} P_{j} Y_{j k}-B_{k} \geq 0 \quad(k=1,2, \cdots, q) \\
\sum_{i=1}^{m} X_{i j}=\sum_{k=1}^{q} Y_{j k} \quad(j=1,2, \cdots, n) \\
X_{i j} \geq 0, Y_{j k} \geq 0 \\
(i=1,2, \cdots, m ; j=1,2, \cdots, n ; k=1,2, \cdots, q)
\end{gathered}
$$

Formula (9) indicates that the trailers from a supply point can only travel through the same freight station; Formula (10) specifies that the trailers to a demand point should come from the same freight station; Formula (11) regulates that the total quantity of goods on the trailers arriving at freight station $j$ should not surpass the capacity of that station; Formula (12) requires that the number of trailers from freight station $j$ to demand point $k$ must satisfy the demand at that point; Formula (13) means the number of trailers entering a freight station should equal that leaving the station; Formula (14) ensures that the parameters are nonnegative.

\subsection{Model of shared freight station design in the H-S T-P network}

In the H-S T-P network, the objective function of the shared freight station design can be expressed as:

$$
\begin{aligned}
& \operatorname{Min} U=\sum_{i=1}^{m} \sum_{j=1}^{n} r C_{i j} X_{i j}+\sum_{j=1}^{n} \sum_{k=1}^{q} r D_{i j} Y_{i j} \\
& +\sum_{i=1}^{m} \sum_{j=1}^{n} a g X_{i j}+\sum_{j=1}^{n} b P_{j} S_{j} \\
& \operatorname{Max} F=\sum_{i=1}^{m} \sum_{j=1}^{n} F_{i j}+\sum_{j=1}^{n} \sum_{k=1}^{q} F_{j k}
\end{aligned}
$$

where, $a$ and $b$ are the coefficients management cost and construction cost of a shared freight station, respectively.

The constraints of the model are as follows:

$$
\frac{\sum_{j=1}^{n} P_{j} K_{j} \pi C^{2}}{E} \geq \alpha
$$

$$
\begin{gathered}
P_{j} M_{j}-P_{j} \sum_{i=1}^{m} X_{i j} \geq 0 \quad(j=1,2, \cdots, n) \\
\sum_{j=1}^{n} P_{j} Y_{j k}-B_{k} \geq 0 \quad(k=1,2, \cdots, q) \\
\sum_{i=1}^{m} X_{i j}=\sum_{k=1}^{q} Y_{j k} \quad(j=1,2, \cdots, n) \\
X_{i j} \geq 0, Y_{j k} \geq 0 \\
(i=1,2, \cdots, m ; j=1,2, \cdots, n ; k=1,2, \cdots, q) \\
A_{i}-\sum_{j=1}^{n} P_{j} X_{i j}=0 \quad(i=1,2, \ldots, m)
\end{gathered}
$$

Formula (22) indicates that the trailers from each supply point must all travel through a shared freight station. The other constraints are the same as those of the model of traditional freight station design in the H-S T-P network.

\subsection{Model solving}

The software LINGO was selected to solve the established model. LINGO is a highly specialized package for solving optimization problems. With a complete set of solving programs and dozens of internal functions, the software can solve both linear and nonlinear equations, and support integer programming, including 0-1 integer programming (i.e. the decision variables can be integers). In addition to convenience and flexibility, LINGO boasts a simple and intuitive input model, timely error prompts and fast execution of commands. The software can exchange data easily with Excel, databases or other software. The model was solved in three steps: 
Converting the multi-objective problem into a single-objective problem (transforming objective function (1) into a constraint); converting the model into LINGO language; substituting the parameters to solve the model.

\section{EMPIRICAL ANALYSIS}

China has the largest highway freight market in the world, which is supported by an extremely complex highway network. However, there is ample room to improve the transport network. Therefore, a region of southern China was selected for empirical analysis.

\subsection{Empirical analysis on the model of traditional freight station design in H-S T-P network}

In the selected region, there are 6 supply points, 9 alternative freight stations and 6 demand points. Several alternative freight stations need to be selected for actual transport. The data on all the nodes in the H-S T-P network are listed in Tables 1-5 below.

Table 1. Capacity (10,000 vehicles/month), construction cost (RMB 10,000 yuan), logistics factor of each alternative freight station

\begin{tabular}{cccccccccc}
\hline & Station 1 & Station 2 & Station 3 & Station 4 & Station 5 & Station 6 & Station 7 & Station 8 & Station 9 \\
\hline Capacity & 2.4705 & 6.722 & 1.5185 & 4.4445 & 1.1575 & 3.3335 & 2.148 & 2.222 & 5.5555 \\
Construction cost & 2,000 & 3,000 & 1,500 & 2,000 & 2,000 & 500 & 500 & 5,000 & 600 \\
Logistics factor & 0.94 & 2.04 & 0.62 & 2.29 & 0.81 & 1.24 & 0.65 & 1.99 & 1.35 \\
\hline
\end{tabular}

Table 2. Supply volume of each supply point (10,000 vehicles/month)

\begin{tabular}{ccccccc}
\hline & Supply point 1 & Supply point 2 & Supply point 3 & Supply point 4 & Supply point 5 & Supply point 6 \\
\hline Supply volume & 2.000 & 1.61 & 1.311 & 1.421 & 0.7 & 2.230 \\
\hline
\end{tabular}

Table 3. Demand volume of each demand point (10,000 vehicles/month)

\begin{tabular}{ccccccc}
\hline & Demand point 1 & Demand point 2 & Demand point 3 & Demand point 4 & Demand point 5 & Demand point 6 \\
\hline Demand volume & 1.5305 & 0.073 & 0.828 & 0.709 & 0.6335 & 1.6775 \\
\hline
\end{tabular}

Table 4. Distance from supply point to alternative freight station $(\mathrm{km})$

\begin{tabular}{lccccccccc}
\hline & Station 1 & Station 2 & Station 3 & Station 4 & Station 5 & Station 6 & Station 7 & Station 8 & Station 9 \\
\hline Supply point 1 & 342.4 & 99.2 & 226 & 199.5 & 458.9 & 149 & 271.8 & 439 & 79 \\
Supply point 2 & 736.8 & 534.2 & 613 & 320.5 & 39 & 540 & 204 & 53.4 & 483 \\
Supply point 3 & 122 & 454 & 204 & 627.7 & 750 & 334 & 652 & 803 & 498.1 \\
Supply point 4 & 335 & 124 & 163.1 & 266 & 574 & 152.5 & 300.4 & 457 & 150 \\
Supply point 5 & 318.2 & 103.5 & 198 & 256 & 484 & 132 & 325 & 465 & 97.1 \\
Supply point 6 & 582 & 321 & 451 & 395 & 651.6 & 369 & 460 & 612 & 261 \\
\hline
\end{tabular}

Table 5. Distance from alternative freight station to demand point $(\mathrm{km})$

\begin{tabular}{lcccccc}
\hline & Demand point 1 & Demand point 2 & Demand point 3 & Demand point 4 & Demand point 5 & Demand point 6 \\
\hline Station 1 & 673.6 & 454 & 330 & 622 & 390.2 & 320 \\
Station 2 & 477.2 & 248 & 184 & 225.2 & 163.6 & 165 \\
Station 3 & 612 & 337 & 203.2 & 303.1 & 272.3 & 204.5 \\
Station 4 & 220 & 90.4 & 344 & 201 & 134 & 243 \\
Station 5 & 134 & 274.2 & 563 & 349 & 404 & 455 \\
Station 6 & 525 & 295 & 276 & 271.8 & 207.3 & 220.4 \\
Station 7 & 265 & 131 & 311 & 175.9 & 220 & 282 \\
Station 8 & 112 & 150 & 452 & 327 & 358 & 426 \\
Station 9 & 416 & 194.7 & 199.9 & 217 & 144 & 140 \\
\hline
\end{tabular}

According to a previous survey, the transportation fee $r$ is RMB 450,000 yuan per 10,000 trailers per km. The monthly management cost per alternative freight station $g$ is RMB 450,000 yuan per 10,000 trailer per $\mathrm{km}$. It is assumed that each alternative freight station can serve for 5 years, and the alternative freight stations cover the entire region, i.e. the coverage rate is $100 \%$ ). The total area of the region is 179,770 $\mathrm{km}^{2}$. The economically feasible transport distance $\mathrm{C}$ of each freight station was set to $200 \mathrm{~km}$. In addition, the monthly construction cost per alternative freight station is denoted as $S_{j}$. On this basis, the following results were obtained through calculation (as shown in Table 6).
In light of the above results, alternative freight stations 2, 3, 8 and 9 were selected for the transport services. Because all goods from the supply points only pass through one freight station, the established network is a single-hub H-S D-P network. Then, the supply and demand volumes of the supply/demand points were increased (Tables 7 and 8) and substituted into the model of traditional freight station design in H-S T-P network. No feasible solution was obtained. In this case, the single-hub H-S D-P network can no longer satisfy the demand, and should be replaced with a multi-hub network. 
Table 6. Calculation results of the model of traditional freight station design

\begin{tabular}{cccc}
\hline Variable & Value & Variable & Value \\
\hline $\mathrm{P}(2)$ & 1.000000 & $\mathrm{X}(5,9)$ & 0.7000000 \\
$\mathrm{P}(3)$ & 1.000000 & $\mathrm{X}(6,9)$ & 2.230000 \\
$\mathrm{P}(8)$ & 1.000000 & $\mathrm{Y}(2,4)$ & 0.7090000 \\
$\mathrm{P}(9)$ & 1.000000 & $\mathrm{Y}(2,5)$ & 0.7120000 \\
$\mathrm{X}(1,9)$ & 2.000000 & $\mathrm{Y}(3,3)$ & 1.311000 \\
$\mathrm{X}(2,8)$ & 1.610000 & $\mathrm{Y}(8,1)$ & 1.537000 \\
$\mathrm{X}(3,3)$ & 1.311000 & $\mathrm{Y}(8,2)$ & $0.7300000 \mathrm{E}-01$ \\
$\mathrm{X}(4,2)$ & 1.421000 & $\mathrm{Y}(9,6)$ & 4.930000 \\
\hline \multicolumn{5}{c}{ Total cost RMB 130.92 million yuan } \\
\hline
\end{tabular}

Table 7. Supply volume of each supply point (10,000 vehicles/month)

\begin{tabular}{ccccccc}
\hline & Supply point 1 & Supply point 2 & Supply point 3 & Supply point 4 & Supply point 5 & Supply point 6 \\
\hline Supply volume & 2.1015 & 2.221 & 1.5135 & 1.706 & 0.984 & 2.569 \\
\hline
\end{tabular}

Table 8. Demand volume of each demand point (10,000 vehicles/month)

\begin{tabular}{lcccccc}
\hline & Demand point 1 & Demand point 2 & Demand point 3 & Demand point 4 & Demand point 5 & Demand point 6 \\
\hline Demand volume & 1.5305 & 1.6295 & 0.728 & 0.609 & 1.3335 & 1.3775 \\
\hline
\end{tabular}

\subsection{Empirical analysis on the model of shared freight} station design in H-S T-P network

The model of shared freight station design in H-S T-P network was applied under the supply and demand volumes in Tables 7 and 8. It is assumed that a and b, the coefficients management cost and construction cost of a shared freight station, are both 1 . Then, the following results were obtained through calculation (as shown in Table 9).

Table 9. Calculation results of the model of shared freight station design

\begin{tabular}{cc}
\hline Variable & Value \\
\hline $\mathrm{P}(2)$ & 1.000000 \\
$\mathrm{P}(3)$ & 1.000000 \\
$\mathrm{P}(8)$ & 1.000000 \\
$\mathrm{P}(9)$ & 1.000000 \\
$\mathrm{X}(1,9)$ & 2.101500 \\
$\mathrm{X}(2,8)$ & 2.221000 \\
$\mathrm{X}(3,3)$ & 1.513500 \\
$\mathrm{X}(4,2)$ & 1.706000 \\
$\mathrm{X}(5,2)$ & 0.099 \\
$\mathrm{X}(5,9)$ & 0.8850000 \\
$\mathrm{X}(6,9)$ & 2.569000 \\
$\mathrm{Y}(2,4)$ & 0.6100000 \\
$\mathrm{Y}(2,5)$ & 1.195000 \\
$\mathrm{Y}(8,1)$ & 1.530000 \\
$\mathrm{Y}(8,2)$ & 0.6910000 \\
$\mathrm{Y}(3,3)$ & 1.513500 \\
$\mathrm{Y}(9,2)$ & 0.9385000 \\
$\mathrm{Y}(9,5)$ & 0.1339000 \\
$\mathrm{Y}(9,6)$ & 4.483100 \\
\hline Total cost & RMB 156.35 million yuan \\
\hline
\end{tabular}

Therefore, alternative freight stations 2, 3, 8 and 9 were selected for transport services.

\subsection{Comparison between traditional and shared freight station designs}

The flows of goods in the traditional and shared freight station designs are illustrated in Figures 3 and 4, respectively. It can be seen that the shared design processed 14,250 (7.14\%) more trailers and incurred RMB 769.5 yuan $(9.83 \%)$ fewer total cost of shared freight station per vehicle than the traditional design.

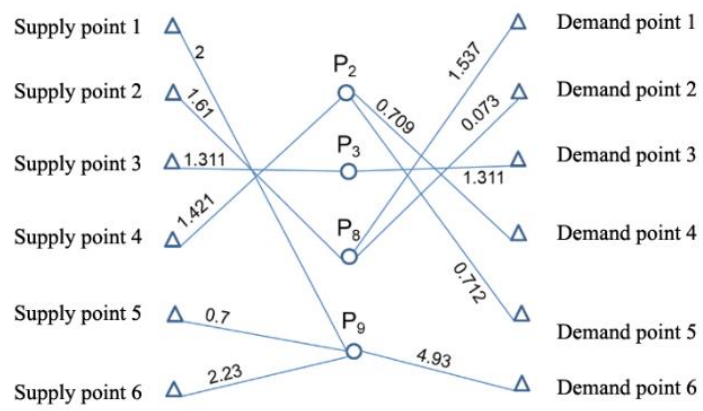

Figure 3. The flow of goods in the traditional freight station design

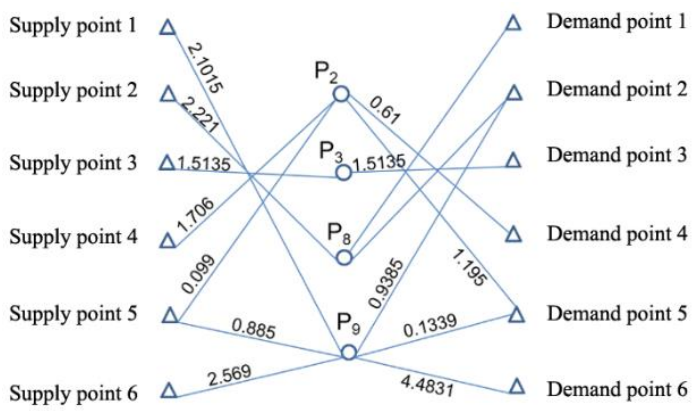

Figure 4. The flow of goods in the shared freight station design

\section{CONCLUSIONS}

Through the above modelling and analysis, it is concluded that, in the H-S T-P network, the shared freight station design makes better use of freight stations than the freight station design in H-S T-P network in the same region. The research results show that shared freight station is the future of T-P transport. The future research will further explore the freight station design from the following aspects: the informatization 
and profit distribution of shared distribution station; the operation of the shared trailer; the functions of demand points.

\section{ACKNOWLEDGMENT}

This work is supported by Scientific Research Project of Hunan Provincial Department of Education: Research on the Truck-Cargo Matching in Highway Drop-and-Pull Transport Based on "Internet +" (Grant No.: 18C1566).

\section{REFERENCES}

[1] Vlk, F. (1985). Handling performance of truck-trailer vehicles: A state-of-the-art survey. International Journal of Vehicle Design, 6(3): 323-361. http://dx.doi.org/10.1504/IJVD.1985.061125

[2] Godbole, S., Lam, N., Mafas, M., Fernando, S., Gad, E., Hashemi, J. (2018). Dynamic loading on a prefabricated modular unit of a building during road transportation. Journal of Building Engineering, 18: 260-269. https://doi.org/10.1016/j.jobe.2018.03.017

[3] Salati, L., Schito, P., Cheli, F. (2017). Wind tunnel experiment on a heavy truck equipped with front-rear trailer device. Journal of Wind Engineering and Industrial Aerodynamics, 171: 101-109. https://doi.org/10.1016/j.jweia.2017.09.016

[4] Wang, H.F., Chan, C.H. (2014). Multi-objective optimisation of automated guided dispatching and vehicle routing system. International Journal of Modelling in Operations Management, 4(1-2): 35-52. https://doi.org/10.1504/IJMOM.2014.063585

[5] Villegas, J.G., Prins, C., Prodhon, C., Medaglia, A.L., Velasco, N. (2013). A matheuristic for the truck and trailer routing problem. European Journal of Operational Research, 230(2): 231-244. https://doi.org/10.1016/j.ejor.2013.04.026

[6] Derigs, U., Pullmann, M., Vogel, U. (2013). Truck and trailer routing-problems, heuristics and computational experience. Computers \& Operations Research, 40(2): 536-546. https://doi.org/10.1016/j.cor.2012.08.007

[7] Mirmohammadsadeghi, S., Ahmed, S. (2015). Memetic heuristic approach for solving truck and trailer routing problems with stochastic demands and time windows. Networks and Spatial Economics, 15(4): 1093-1115. https://doi.org/10.1007/s11067-014-9282-2

[8] Galić, A., Carić, T., Fosin, J. (2013). The case study of implementing the delivery optimization system at a fastmoving consumer goods distributer. Promet-Traffic \& Transportation, 25(6): 595-603. https://doi.org/10.7307/ptt.v25i6.1296

[9] Vlk, F. (1982). Lateral dynamics of commercial vehicle combinations a literature survey. Vehicle System Dynamics, 11(5-6): 305-324. https://doi.org/10.1080/00423118208968702

[10] Pflug, H.C. (1986). Lateral dynamic behaviour of trucktrailer combinations due to the influence of the load*. Vehicle System Dynamics, 15(3): 155-177. https://doi.org/10.1080/00423118608968849

[11] Kim, J.J., Lee, S., Kim, M., You, D., Lee, S.J. (2017). Salient drag reduction of a heavy vehicle using modified cab-roof fairings. Journal of Wind Engineering and
Industrial Aerodynamics, 164:

$138-151$ https://doi.org/10.1016/j.jweia.2017.02.015

[12] Horta, M., Coelho, F., Relvas, S. (2016). Layout design modelling for a real world just-in-time warehouse. Computers \& Industrial Engineering, 101: 1-9. https://doi.org/10.1016/j.cie.2016.08.013

[13] Rakesh, V., Adil, G.K. (2015). Layout optimization of a three dimensional order picking warehouse. IFACPapersOnLine, $\quad 48(3)$ : 1155-1160. https://doi.org/10.1016/j.ifacol.2015.06.240

[14] Melo, M.T., Nickel, S., Da Gama, F.S. (2006). Dynamic multi-commodity capacitated facility location: a mathematical modeling framework for strategic supply chain planning. Computers \& Operations Research, 33(1): 181-208 https://doi.org/10.1016/j.cor.2004.07.005

[15] Zhong, H.L., Wu, C., Zhang, G.X., Cai, W.X. (2013). Freight station location of inland port semi-Trailer swap transport organization. Journal of Transportation Systems Engineering and Information Technology, 13(3): 126-131. 6744.2013.03.010

[16] Zhou, Y., Zuo, T.L., Song, X.Q, Wang, W.Y. (2015). Comparison of layout scheme of drop-and-pull transport terminal in coastal port based on simulation. Port Engineering Technology, 52(2): 6-8. https://doi.org/10.16403/j.cnki.ggjs20150202

[17] Labadi, K., Benarbia, T., Barbot, J.P., Hamaci, S., Omari, A. (2014). Stochastic petri net modeling, simulation and analysis of public bicycle sharing systems. IEEE Transactions on Automation Science and Engineering, 12(4): 1380-1395.. https://doi.org/10.1109/TASE.2014.2336874

[18] Yang, X.H., Cheng, Z., Chen, G., Wang, L., Ruan, Z.Y., Zheng, Y.J. (2018). The impact of a public bicyclesharing system on urban public transport networks. Transportation Research Part A: Policy and Practice, 107: 246-256. https://doi.org/10.1016/j.tra.2017.10.017

[19] Mohammadi, B., Shirouyehzad, H. (2018). Developing a multi-commodity multi-period mathematical model based on the travelling salesman problem for solving bike sharing rebalancing problem. International Journal of Modelling in Operations Management, 7(1): 59-74. https://doi.org/10.1504/IJMOM.2018.095668

[20] Zhu, X., Li, J., Liu, Z., Yang, F. (2017). Location deployment of depots and resource relocation for connected car-sharing systems through mobile edge computing. International Journal of Distributed Sensor Networks, $13(6)$ : https://doi.org/10.1177/1550147717711621

[21] Dalalah, D., Al-Rawabdeh, W.A. (2013). Cost driven traffic assignment in transportation networks. International Journal of Modelling in Operations Management, 3(3-4): 219-240. https://doi.org/10.1504/ijmom.2013.058333

[22] Feng, M., Cheng, Y.R. (2010). Research on warehouse layout optimization and freight volume distribution of steel enterprises. Journal of Wuhan University of Technology, 32(11): 126-130.

[23] Jin, F.H., Li, Q.X., Sun, P.S. (2010). Evaluation and cluster analysis of regional logistics development level based on field theory. Economic Geography, 30(7): 1138-1143. https://doi.org/10.15957/j.cnki.jjdl.2010.07.011 


\section{APPENDIX}

LINGO solution for the non-shared drop-and-pull stations in hub-and-spoke networks

[OBJ]MAX=@SUM(ROUTE1(I,J):(1/(C(I,J)^2) $)^{*} \mathrm{P}(\mathrm{J}) * \mathrm{Q}(\mathrm{J})$ *X(I,J ) $))+@ S U M\left(R O U T E 2(J, K):\left(1 /\left(\mathrm{D}(\mathrm{J}, \mathrm{K})^{\wedge} 2\right)\right)^{*} \mathrm{P}(\mathrm{J})^{*} \mathrm{Q}\right.$ $(\mathrm{J}) * \mathrm{Y}(\mathrm{J}, \mathrm{K}))$;

@ SUM(ROUTE1(I,J):T*P(J)*C(I,J)*X(I,J)+g*P(J)*X(I,J))+ @ SUM(ROUTE2 $(\mathrm{J}, \mathrm{K}): \mathrm{T} * \mathrm{P}(\mathrm{J}) * \mathrm{D}(\mathrm{J}, \mathrm{K}) * \mathrm{Y}(\mathrm{J}, \mathrm{K}))+$ @ SUM ( WAREHOUSES $(\mathrm{J}): \mathrm{P}(\mathrm{J}) * \mathrm{U}(\mathrm{J}))<=\mathrm{Z}$;

@ SUM(WAREHOUSES(J):P(J)*K(J)*3.14*40000/179770) $>=\alpha$;

$@$ FOR $($ WAREHOUSES $(\mathrm{J}): \mathrm{A}(\mathrm{I})=\mathrm{P}(\mathrm{J}) * \mathrm{X}(\mathrm{I}, \mathrm{J}))$;

@FOR(WAREHOUSES $(\mathrm{J}): \mathrm{B}(\mathrm{k})=\mathrm{P}(\mathrm{J}) * \mathrm{Y}(\mathrm{J}, \mathrm{K}))$;

@FOR(WAREHOUSES(J):P(J)*M(J)>=(@SUM(FROM(I): $\mathrm{P}(\mathrm{J}) * \mathrm{X}(\mathrm{I}, \mathrm{J}))))$;

@FOR(TO(K): @SUM(WAREHOUSES(J):P(J)*Y(J,K))>= $\mathrm{B}(\mathrm{K}))$;

@FOR(WAREHOUSES(J): @ SUM(FROM(I):X(I,J))=@SU $\mathrm{M}(\mathrm{TO}(\mathrm{K}): \mathrm{Y}(\mathrm{J}, \mathrm{K})))$;

@FOR(ROUTE1 $(\mathrm{I}, \mathrm{J}): \mathrm{X}(\mathrm{I}, \mathrm{J})>=0)$;

@FOR(ROUTE2 $(\mathrm{J}, \mathrm{K}): \mathrm{Y}(\mathrm{J}, \mathrm{K})>=0)$;

@FOR(WAREHOUSES(J): @BIN $(\mathrm{P}(\mathrm{J})))$;

@FOR(WAREHOUSES(J):P(J)=@IF(@SUM(FROM(I):X(I J))\#NE\#0,1,0));
LINGO solution for the shared drop-and-pull stations in huband-spoke networks

[OBJ]MAX=@SUM(ROUTE1(I,J):(1/(C(I,J)^2))*P(J)*Q $(\mathrm{J})$

*X(I,J ) $))+@ S U M\left(R O U T E 2(J, K):\left(1 /\left(D(J, K)^{\wedge} 2\right)\right) * \mathrm{P}(\mathrm{J}) * \mathrm{Q}\right.$ $\left.(\mathrm{J})^{*} \mathrm{Y}(\mathrm{J}, \mathrm{K})\right)$;

@ SUM(ROUTE1(I,J):T*P(J)*C(I,J)*X(I,J)+g*P(J)*X(I,J))+ @SUM(ROUTE2 $(\mathrm{J}, \mathrm{K}): \mathrm{T} * \mathrm{P}(\mathrm{J}) * \mathrm{D}(\mathrm{J}, \mathrm{K}) * \mathrm{Y}(\mathrm{J}, \mathrm{K}))+@ \mathrm{SUM}($ WAREHOUSES $(\mathrm{J}): \mathrm{P}(\mathrm{J}) * \mathrm{U}(\mathrm{J}))<=\mathrm{Z}$;

@SUM(WAREHOUSES(J):P(J)*K(J)*3.14*40000/179770) $>=\alpha$;

@ FOR(WAREHOUSES(J):P(J)*M(J)>=(@SUM(FROM(I): $\left.\left.\left.\mathrm{P}(\mathrm{J})^{*} \mathrm{X}(\mathrm{I}, \mathrm{J})\right)\right)\right)$;

@FOR(TO(K):@SUM(WAREHOUSES(J):P(J)*Y $(\mathrm{J}, \mathrm{K}))>=$ $\mathrm{B}(\mathrm{K}))$;

@FOR(WAREHOUSES(J): @SUM(FROM(I):X(I,J))=@SU $\mathrm{M}(\mathrm{TO}(\mathrm{K}): \mathrm{Y}(\mathrm{J}, \mathrm{K})))$;

@ FOR(ROUTE1 $(\mathrm{I}, \mathrm{J}): \mathrm{X}(\mathrm{I}, \mathrm{J})>=0)$;

@ FOR(ROUTE2 $(\mathrm{J}, \mathrm{K}): \mathrm{Y}(\mathrm{J}, \mathrm{K})>=0)$;

@FOR(WAREHOUSES(J): @BIN(P(J)));

@FOR(WAREHOUSES(J):P(J)=@IF(@SUM(FROM(I):X(I ,J) )\#NE\#0,1,0));

@FOR(FROM(I):A(I)=@SUM(WAREHOUSES(J):P(J)*X(I ,J)));

END END 